\title{
An Efficient Synthesis of Tetraethyl Fluoromethylenediphosphonate and Derivatives from Diethyl Dibromofluoromethylphosphonate
}

\author{
Bogdan Iorga, Frédéric Eymery and Philippe Savignac \\ Laboratoire Hétéroéléments et Coordination, DCPH, CNRS et Ecole Polytechnique \\ 91128 Palaiseau, France.

\begin{abstract}
Treatment of diethyl 1,1-dibromo-1-fluoromethylphosphonate with $n$-BuLi (1:1) at low temperature affords by self-trapping in quantitative yield the lithiated derivative of tetraethyl fluoromethylenediphosphonate which is reacted with alkylating and halogenating agents or converted with high selectivity into (E) diethyl fluorovinylphosphonates by reaction with carbonyl compounds.
\end{abstract}

Tetraalkyl fluoromethylenediphosphonates are isopolar analogues of pyrophosphates. ${ }^{1}$ In the acid form they have been proposed as a therapeutic preparation for the treatment of diseases associated with increased desorption of bones. Several procedures for the synthesis of tetraalkyl monofluoromethylenediphosphonates were developed in the past, but these methods appear to have only limited potential. In 1981, two groups reported independently the electrophilic fluorination of tetraisopropyl methylenediphosphonate by treatment of the corresponding carbanion ( $\mathrm{Li}, \mathrm{Na}, \mathrm{K}$ ) with $\mathrm{FClO}_{3}{ }^{2,3}$ The reaction gives an hardly separable mixture of mono- and difluoromethylenediphosphonates, which is the major drawback with the electrophilic fluorination. Another variation using the reaction of diisopropyl 1lithio-1-fluoromethylphosphonate with the diisopropyl chlorophosphate gave the desired tetraisopropyl fluoromethylenediphosphonate in moderate yield (37\%). ${ }^{4}$ The tetraisopropyl fluoromethylenediphosphonate was also isolated in $40 \%$ yield in attempts to react the diisopropyl 1-lithio-1-chloro-1fluoromethylphosphonate with electrophiles. ${ }^{4}$

We describe here an attractive route to the tetraethyl fluoromethylenediphosphonate $\mathbf{4 a}$, and its derivatives, through a self-trapping reaction between $\mathbf{1}$ and its metallated derivative, the 1-lithio-1-bromo1-fluoromethylphosphonate $\mathbf{5}$. Carbanion $\mathbf{5}$ is generated by an halogen-metal exchange reaction between the $n$-BuLi and the diethyl fluorodibromomethylphosphonate $\mathbf{1}$, which is a readily accessible starting material prepared in pure form with $85 \%$ yield 5 from $(\mathrm{EtO})_{3} \mathrm{P}$ and $\mathrm{CFBr}_{3}$.

Throughout our experiments we observed that the reaction of 1 with TMSCl must be effectively controlled. Thus, simultaneous addition of phosphonate $\mathbf{1}$ and TMSCl (1.1 eq.) (route A) to a THF solution of

*Fax. (+33) 01693339 90.E-mail : dcph@poly.polytechnique.fr 
$n$-BuLi (2 eq.) at low temperature gives the previously described 6 carbanion $2\left(\delta^{31} \mathrm{P}(\mathrm{THF})=+52.8 \mathrm{ppm}, \mathrm{d}\right.$, $\left.{ }^{2} J_{\mathrm{PF}}=67.2\right)$. Reaction of $\mathbf{2}$ with diethyl chlorophosphate produces mainly the diethyl chlorofluoromethylphosphonate resulting of an halogen-metal exchange reaction. The desired product $\mathbf{4 a}$ is formed in less than $10 \%$ (Scheme 1). By contrast, addition of phosphonate 1 to a THF solution of $n$-BuLi (1 eq.) in the absence of $\mathrm{TMSCl}$ (route B) proceeds at low temperature to give cleanly and quantitatively the stable lithiated tetraethyl fluoromethylenediphosphonate $\mathbf{3}$, fully identified by its spectroscopic data $\left(\delta^{31} \mathrm{P}(\mathrm{THF})=+34.7 \mathrm{ppm}, \mathrm{d},{ }^{2} J_{\mathrm{PF}}=57 \mathrm{~Hz}\right.$ and $\left.\delta^{19} \mathrm{~F}(\mathrm{THF})=-280 \mathrm{ppm}, \mathrm{t},{ }^{2} J_{\mathrm{FP}}=57 \mathrm{~Hz}\right)$. Subsequent addition of the brownish solution of $\mathbf{3}$ to an aqueous solution of $\mathrm{HCl} 3 \mathrm{M}$ produces the tetraethyl fluoromethylenediphosphonate $\mathbf{4 a}$ in quantitative yield.

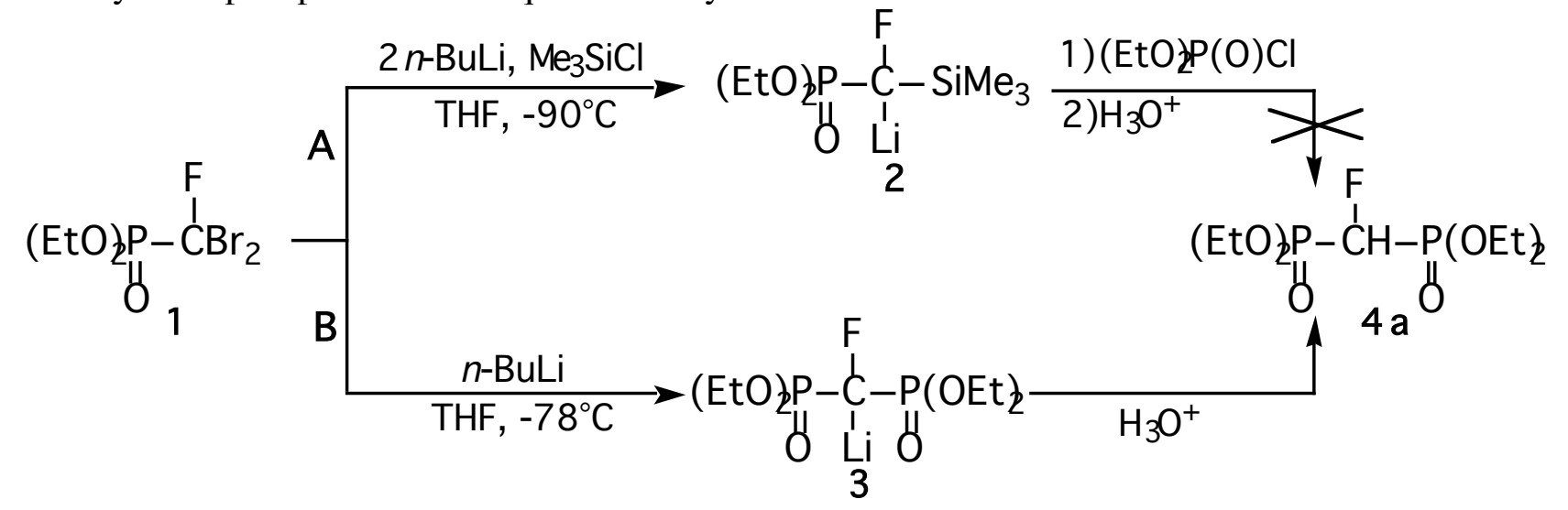

Scheme 1.

The formation of $\mathbf{3}$ may be reasonably interpreted in terms of steric and electronic factors. It is due to the attack of the diethyl 1-lithio-1-bromo-1-fluoromethylphosphonate 5 on the phosphoryl group of the phosphonate 1 to give the transient tetraethyl bromofluoromethylenediphosphonate 6 (Scheme 2). This intermediate undergoes an halogen-metal exchange reaction with $n$-BuLi to give $\mathbf{3}$. The complete transformation of 1 to 3 needs 1 eq. of $n$ - BuLi and the $\mathrm{LiCFBr}_{2}$ formed does not participate in the reaction. To support this mechanism, the reaction was performed in the presence of 2,3-dimethyl-2-butene in excess. The anion 3 was generated as above and the carbene resulting from the decomposition of $\mathrm{LiCFBr}_{2}$ was trapped to produce the 1-bromo-1-fluoro-2,2,3,3-tetramethylcyclopropane identified in ${ }^{19} \mathrm{~F}-\mathrm{NMR}$ as a singlet at $-138.8 \mathrm{ppm}^{7}$

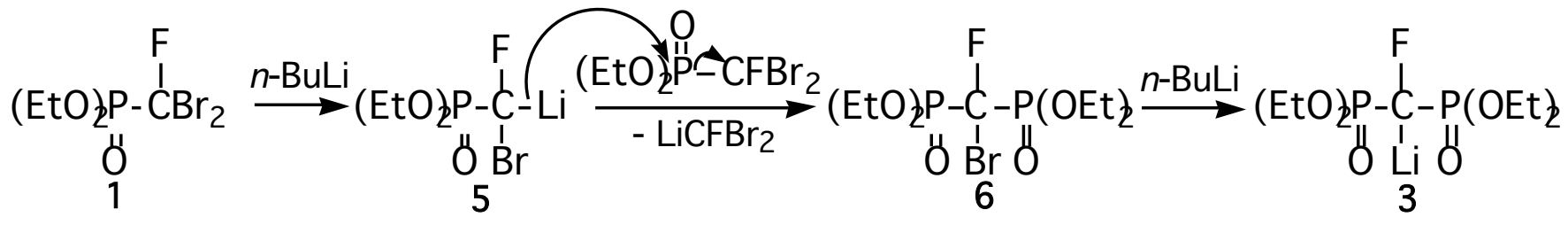

Scheme 2.

When the reaction was applied in the experimental conditions of route $\mathbf{B}$ to an electrophilic and sterically more hindered phosphonate partner, 8 the diethyl trichloromethylphosphonate, the ethyl 1,1dichloro-propylphosphonic salt resulting from a dealkylation at phosphorus was the only reaction product (Scheme 3). 9 


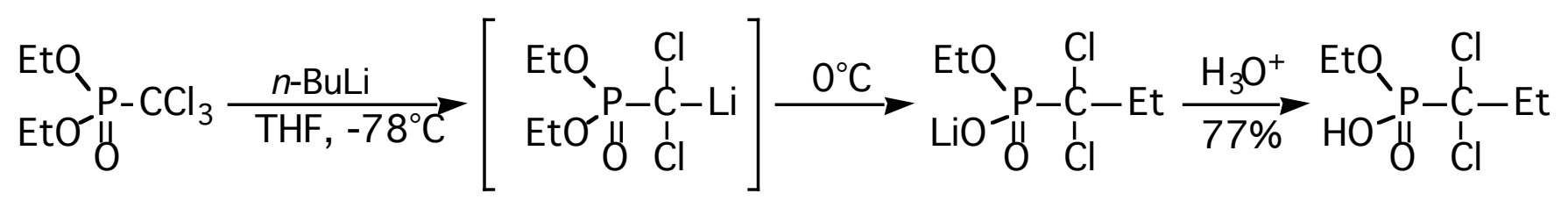

Scheme 3.

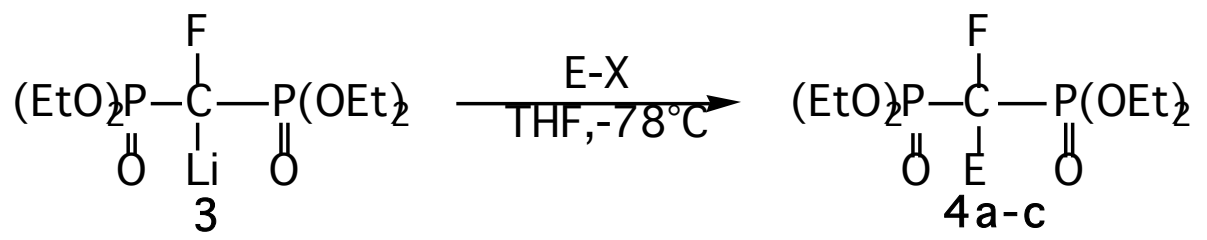

Table 1.

Scheme 4.

\begin{tabular}{|c|c|c|c|c|c|c|}
\hline 4 & $\mathrm{E}$ & $\begin{array}{c}\delta^{31} \mathrm{P}(\mathrm{ppm}) \\
\left(\mathrm{CDCl}_{3}\right)\end{array}$ & $\begin{array}{c}\delta_{\mathrm{CFE}}{ }^{19} \mathrm{~F} \\
(\mathrm{ppm})\left(\mathrm{CDCl}_{3}\right. \\
)\end{array}$ & $\begin{array}{c}\delta_{\mathrm{CFE}}{ }^{1} \mathrm{H} \\
\left.(\mathrm{ppm})(\stackrel{\mathrm{CDCl}}{3})^{-\mathrm{C}}\right)\end{array}$ & $\begin{array}{c}\delta_{\underline{\mathrm{CFE}}}{ }^{13 \mathrm{C}} \\
(\mathrm{ppm})\left(\mathrm{CDCl}_{3}\right)\end{array}$ & $\begin{array}{c}\text { Yields } \\
(\%)\end{array}$ \\
\hline $\mathbf{a}$ & $\mathrm{H}$ & $\left(\mathrm{d},{ }^{2} J_{\mathrm{PF}}=63.3\right)$ & $\left(\mathrm{t},{ }^{2} J_{\mathrm{PF}}=63.0\right)$ & $\begin{array}{c}5.03\left(\mathrm{dt},{ }^{2} J_{\mathrm{PH}}=13.6,\right. \\
\left.{ }^{2} J_{\mathrm{FH}}=45.9\right)\end{array}$ & $\begin{array}{c}84.5\left(\mathrm{dt},{ }^{1} J_{\mathrm{PC}}=156.5\right. \\
\left.{ }^{1} J_{\mathrm{FC}}=191.5\right)\end{array}$ & 95 \\
\hline b & $\mathrm{Cl}$ & $\left(\mathrm{d},{ }^{2} J_{\mathrm{PF}}^{6.5}=76.0\right)$ & $\left(\mathrm{t},{ }^{-142.3} J_{\mathrm{PF}}=75.9\right)$ & - & $\begin{array}{c}101.8\left(\mathrm{dt},{ }^{1} J_{\mathrm{PC}}=170.0\right. \\
\left.{ }^{1} J_{\mathrm{FC}}=268.6\right)\end{array}$ & 87 \\
\hline c & $\begin{array}{c}\mathrm{M} \\
\mathrm{e}\end{array}$ & $\begin{array}{c}12.7 \\
\left(\mathrm{~d},{ }^{2} J_{\mathrm{PF}}=72.5\right)\end{array}$ & $\left(\mathrm{t},{ }^{2} J_{\mathrm{PF}}=72.0\right)$ & $\begin{array}{c}5.03\left(\mathrm{dt},{ }^{3} J_{\mathrm{PH}}=15.4,\right. \\
\left.{ }^{3} J_{\mathrm{FH}}=25.7\right)\end{array}$ & $\begin{array}{c}93.2\left(\mathrm{dt},{ }^{1} J_{\mathrm{PC}}=160.1\right. \\
\left.{ }^{1} J_{\mathrm{FC}}=185.3\right)\end{array}$ & 96 \\
\hline
\end{tabular}

As is evident from electronic factors, the carbanion $\mathbf{3}$ does not possess the same extent of significant synthetic advantages than the carbanion 2. Effectively, the stabilizing effect of the three attracting groups profoundly affects its reactivity toward electrophilic reagents. However, the tertiary carbon of $\mathbf{3}$ may also be further elaborated by either alkylation, halogenation or olefination with the appropriate reagents (Scheme 4). For example, treatment of 3 with methyl iodide ( 3 eq.) and hexachloroethane ( 2 eq.) at low temperature, followed by warming to room temperature provided the derivatives $\mathbf{4 b}$ and $\mathbf{4 c}$ in good yields (Table 1). Ethyl iodide does not react in these conditions even at $30^{\circ} \mathrm{C}$, as well as 1,2-dibromo-1,1,2,2-tetrafluoroethane. Attempts to brominate the carbanion 2 with 1,2-dibromo-1,1,2,2-tetrachloroethane result exclusively in the chlorinated derivative $\mathbf{4 b}$ instead of the brominated one.<smiles>CCO[P+](=O)C(F)([Al])[Pb](=O)OCC</smiles>

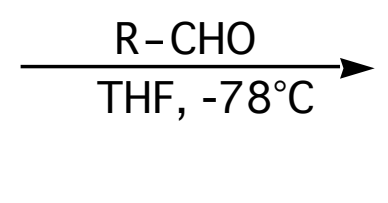<smiles>[R]/C=C(/F)[P+](=O)OCC</smiles>

Scheme 5.

A clear illustration of the advantages of this novel synthetic procedure is provided by the conversion of $\mathbf{3}$ to vinylphosphonates $\mathbf{8}$ of controlled geometry. ${ }^{10}$ In this regard, the anion $\mathbf{3}$ has been found to be a highly useful reagent for the facile transformation of a variety of aromatic and heteroaromatic aldehydes into diethyl 1-fluorovinylphosphonates 8 (Scheme 5). The olefination reaction proceeds readily and cleanly at low temperature to afford the formation of the $\mathrm{E}$ isomer with a high degree of stereoselectivity (88 to $93 \%$ ) in 
good to excellent yields as exemplified by the preparation of 8a-e (Table 2). In this regard, the previously reported $^{6 c}$ Peterson reaction between 2 and aromatic aldehydes was not highly stereoselective and gave a mixture of $\mathrm{E}$ and $\mathrm{Z}$ isomers in about 70/30 ratio. With enolisable ketones, the anion 3 undergoes mainly protonation as a consequence of its low nucleophilicity, whereas $\mathbf{2}$ is a better nucleophile as previously demonstrated. $6 \mathrm{c}$

These present preliminary results clearly demonstrate that the diethyl fluorodibromomethylphosphonate $\mathbf{1}$ is an ideal precursor for the preparation of the tetraethyl fluoromethylenediphosphonate $\mathbf{4 a}$ and derivatives. It gives superior results than $\mathbf{2}$ for the preparation of (E)vinylphosphonates.

\section{Table 2}

\begin{tabular}{|c|c|c|c|c|c|c|}
\hline 8 & $\mathrm{R}$ & $\begin{array}{c}\delta^{31} \mathrm{P}(\mathrm{ppm}) \\
\left(\mathrm{CDCl}_{3}\right)\end{array}$ & $\begin{array}{c}\delta_{\mathrm{PCF}}{ }^{19}{ }^{19} \mathrm{~F}(\mathrm{ppm}) \\
\left(\mathrm{CDCl}_{3}\right)\end{array}$ & $\begin{array}{c}\delta_{\mathrm{RC}}{ }^{\mathrm{H}}{ }^{1} \mathrm{H}(\mathrm{ppm}) \\
\left(\mathrm{CDCl}_{3}\right)\end{array}$ & $\begin{array}{c}\mathrm{E}: \mathrm{Z}(\%) \\
\left({ }^{19} \mathrm{~F}-\mathrm{NMR}\right)\end{array}$ & $\begin{array}{l}\text { Yields } \\
(\%)^{*}\end{array}$ \\
\hline $\mathbf{a}$ & & $4.0\left(\mathrm{~d},{ }^{2} J_{\mathrm{PF}}=98.0\right)$ & $-127.2\left(\mathrm{~d},{ }^{2} J_{\mathrm{PF}}=98.2\right)$ & $\begin{array}{c}6.76\left(\mathrm{dd},{ }^{3} J_{\mathrm{PH}}=8.7\right. \\
\left.{ }^{3} J_{\mathrm{FH}}=42.2\right)\end{array}$ & $93: 7$ & 92 \\
\hline b & & $4.3\left(\mathrm{~d},{ }^{2} J_{\mathrm{PF}}=97.7\right)$ & $-128.4\left(\mathrm{~d},{ }^{2} J_{\mathrm{PF}}=97.8\right)$ & $\begin{array}{c}6.77\left(\mathrm{dd},{ }^{3} J_{\mathrm{PH}}=8.5,\right. \\
\left.{ }^{3} J_{\mathrm{FH}}=42.5\right)\end{array}$ & $93: 7$ & 90 \\
\hline c & & $3.8\left(\mathrm{~d},{ }^{2} J_{\mathrm{PF}}=97.5\right)$ & $-128.3\left(\mathrm{~d},{ }^{2} J_{\mathrm{PF}}=97.3\right)$ & $\begin{array}{c}6.77\left(\mathrm{dd},{ }^{3} J_{\mathrm{PH}}=8.7\right. \\
\left.{ }^{3} J_{\mathrm{FH}}=42.2\right)\end{array}$ & $93: 7$ & 90 \\
\hline d & & $3.6\left(\mathrm{~d},{ }^{2} J_{\mathrm{PF}}=91.9\right)$ & $-125.7\left(\mathrm{~d},{ }^{2} J_{\mathrm{PF}}=92.0\right)$ & $\begin{array}{c}6.78\left(\mathrm{dd},{ }^{3} J_{\mathrm{PH}}=7.9\right. \\
\left.{ }^{3} J_{\mathrm{FH}}=39.8\right)\end{array}$ & $92: 8$ & 87 \\
\hline e & & $3.8\left(\mathrm{~d},{ }^{2} J_{\mathrm{PF}}=98.7\right)$ & $-126.9\left(\mathrm{~d},{ }^{2} J_{\mathrm{PF}}=99.8\right)$ & $\begin{array}{c}6.94\left(\mathrm{dd},{ }^{3} J_{\mathrm{PH}}=8.5,\right. \\
\left.{ }^{3} J_{\mathrm{FH}}=42.5\right)\end{array}$ & $88: 12$ & 83 \\
\hline
\end{tabular}

* After flash chromatography (hexane / AcOEt, 70/30).

\section{Aknowledgements}

We are grateful to the CNRS and Ecole Polytechnique for financial support to B.I. Thanks are addressed to Dr. Jean Villieras (UMR CNRS 6513) for fruitful discussion.

\section{References and Notes}

1. (a) Engel, R. Chem. Rev. 1977, 77, 349. (b) Hilderbrand, R. L. in The Role of Phosphonates in Living Systems, CRC Press, Boca Raton, FL, 1983, 55-96.

2. McKenna, C. E., Shen, P.-D. J. Org. Chem. 1981, 46, 4573-4576.

3. Blackburn, G. M., England, D. A., Kolkmann, F. J. Chem. Soc., Chem. Commun. 1981, 930-932.

4. Blackburn, G. M., Brown, D., Martin, S. J., Parratt, M. J. J. Chem. Soc., Perkin Trans. 1 1987, $181-186$.

5. Waschbüsch, R., Carran, J., Savignac, P. C.R. Acad. Sci. Paris 1998, 1, 49-52.

6. (a) Patois, C., Savignac, P. J. Chem. Soc., Chem. Commun. 1993, 22, 1711-1712. (b) Berté-Verrando, S., Nief, F., Patois, C., Savignac, P. J. Chem. Soc., Perkin Trans. 1 1994, 821-824. (c) Waschbüsch, R., Carran, J., Savignac, P. $\quad$ Tetrahedron 1996, 52, 14199-14216. (d) Waschbüsch, R., Carran, J., Savignac, P. J. Chem. Soc., Perkin Trans. $1 \quad$ 1997, 1135-1139. (e) Waschbüsch, R., Carran, J., Savignac, P. Tetrahedron 1997, 53, 6391-6400. 
7. Two values have been reported for 1-bromo-1-fluoro-2,2,3,3-tetramethylcyclopropane: -141.2 ppm: Burton, D. J.; Hahnfeld, J. L. J. Org. Chem. 1977, 42, 828-831; -140.4 ppm: M. J. Van Hamme, Ph.D. Thesis, The University of Iowa, 1974.

8. (a) Kirby, A. J.; Warren, S. G. in The Organic Chemistry of Phosphorus, Elsevier, 1967, 310-311. (b) Kennard, K. C.; Hamilton, C. S. J. Amer. Chem. Soc. 1955, 77, 1156-1159.

9. Selected spectral data for ethyl 1,1-dichloropropylphosphonic acid: ${ }^{31} \mathrm{P}-\mathrm{RMN}\left(\mathrm{CDCl}_{3}\right):+12.0(\mathrm{~s}) ;{ }^{1} \mathrm{H}-\mathrm{RMN}\left(\mathrm{CDCl}_{3}\right)$ : $1.30\left(\mathrm{t},{ }^{4} J_{\mathrm{PH}}=7.2,3 \mathrm{H}, \mathrm{CH}_{3} \mathrm{CH}_{2} \mathrm{CCl}_{2}\right), 1.42\left(\mathrm{t},{ }^{4} J_{\mathrm{PH}}=7.1,3 \mathrm{H}, \mathrm{CH}_{3} \mathrm{CH}_{2} \mathrm{O}\right), 2.41\left(\mathrm{p},{ }^{3} J_{\mathrm{PH}^{3}}{ }^{3} J_{\mathrm{HH}}=7.0,2 \mathrm{H}, \mathrm{CH}_{2} \mathrm{CCl}_{2}\right)$, $4.37\left(\mathrm{t},{ }^{3} J_{\mathrm{PH}}={ }^{3} J_{\mathrm{HH}}=7.2,2 \mathrm{H}, \underline{\mathrm{H}}_{2} \mathrm{O}\right), 9.64(\mathrm{bs}, 1 \mathrm{H}, \mathrm{OH}) ;{ }^{13} \mathrm{C}-\mathrm{RMN}\left(\mathrm{CDCl}_{3}\right): 8.8\left(\mathrm{~d},{ }^{3} \mathrm{JCC}_{\mathrm{PC}}=7.6, \underline{\mathrm{CH}}_{3} \mathrm{CH}_{2} \mathrm{CCl}_{2}\right), 17.1$

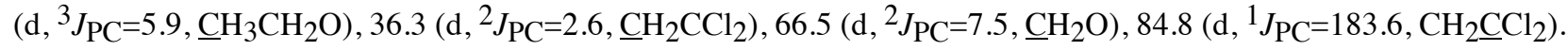

10. (a) Blackburn, G. M., Parratt, M. J. J. Chem. Soc., Chem. Commun. 1982, 1270-1271. (b) Blackburn, G. M., Parratt, M. J. J. Chem. Soc., Perkin Trans. 1 1986, 1417-1424. 